\title{
A ReSEARCH ON COMPREHENSION DIFFERENCES BETWEEN Print AND SCREen REAdING
}

\author{
Szu-Yuan Sun \\ College of Management, National Kaohsiung First University of Science and Technology, Taiwan \\ Chich-Jen Shieh* \\ Department of International business at Chang Jung Christian University, Taiwan \\ Kai-Ping Huang \\ School of Management at University of Technology, Sydney
}

\begin{abstract}
Since the 1980s, extensive research has been conducted comparing reading comprehension from printed text and computer screens. The conclusions, however, are not very consistent. As reading from computer screens requires a certain degree of individual technical skill, such variables should be objectively taken into consideration when conducting an experiment regarding the comparison between print and screen reading. This study analyses the difference in the level of understanding of the two presentational formats (text on printed pages and hypertext on computer screens) for people between 45-54 years of age (i.e. "middleaged" adults). In our experimental findings there were no significant differences between the levels of comprehension for print and screen presentations. With regard to individual differences in gender, age group and educational level, the findings are as follows: gender and education effects on print reading comprehension performance were significant, while those on screen reading comprehension performance were not. For middle-aged computer learners, the main effect of age group on both print and screen reading comprehension performance was insignificant. In contrast, linear texts of traditional paper-based material are better for middle-aged readers' literal text comprehension, while hypertext is beneficial to their inferential text comprehension. It is also suggested that hypermedia could be used as a cognitive tool for improving middle-aged adults' inferential abilities on reading comprehension, provided that they were trained adequately to use available computers.
\end{abstract}

Key words: adult learning, media in education, lifelong learning, multimedia/hypermedia systems, screen reading, print reading, ANOVA, education effect, age group effect

JEL: 1210

1

\section{Introduction}

Reading is a very important way for people to acquire information and knowledge. It requires many mental and cognitive processes including: attention, pattern recognition, memory, knowledge, reasoning and problem solving. Some researchers claim that reading ability is partly dependent on the efficiency of component reading processes (e.g. Perfetti, 1985; Sinatra \& Royer, 1993) and that text comprehension entails two levels of information processing: (1) the technical process of phonological decoding and word recognition, (2) the comprehension process of creating a coherent representation of the meaning of the text (e.g. Graesser, Singer \& Trabasso, 1994; Just \& Carpenter, 1987). According to Gough and Tunmer (1986) and Gough, Juel and Griffith (1992), reading ability can be described as a straightforward amalgamation of word reading and reading comprehension skills. To become a competent reader, one must be able to recognise words in order to understand individual sentences as well as to combine their meanings in order to provide an interpretation of the text as a whole. Since reading is considered a pervasive and vital activity in our lives, a substantial amount of 
research has been done on word reading and reading comprehension skills in the past (e.g. Oakhill \& Yuill, 1996; Seymour \& Evans, 1994; Stanovich, 1986; Wagner, Torgesen \& Rashotte, 1994). Reading comprehension requires a higher level of cognitive and linguistic skill than just basic word reading, even though comprehension tasks cannot be successfully completed without a basic level of word reading skills. Cornoldi and Oakhill (1996) point out that the most important elements of reading comprehension are the ability to search out and understand the pieces of information available in the text (literal text comprehension), as well as the ability to make connections between different parts of the text, in order to fully understand the intended meaning (inferential text comprehension). Students who read texts in print scored significantly better on the reading comprehension test than students who read the texts digitally (Mangen, Walgermo \& Brønnick, 2013).

Reading from printed pages is the traditional mode of reading, although the rapid development of computer and information technologies has contributed to the increased volume of material that people can read from computer screens. Although the demise of the printed page did not come about as forecasted in the 1980 s, reading from screen has now become a more frequent and accepted means with the widespread adoption of computer networks, CD/DVD-ROMs, e-mail, e-learning/ on-line learning and other web media. In addition to the modality of information presentation, the manner of screen reading is quite different from that of print reading. This includes the dynamic aspects of scrolling text on screen, a subject's position in relation to the screen and familiarity with the processes of scrolling and paging (Gould, Alfaro, Barnes, Finn, Grischkowsky \& Minuto, 1987; Hansen \& Haas, 1988; Piolat, Roussey \& Thunin, 1997). Duchnicky and Kolers (1983) found that the upward movement of scrolling text on screen might have reduced the difficulty normally attributed to reading long lines (i.e. finding the beginning of the next line). Agarwal-Hollands and Andrews (2001) indicated that the computer and its scrolling devices put users in a less powerful position in relation to reading whole texts. Gould et al. (1987) expressed that reading from screen may be more difficult, although the specific responsible factors seem to have been rather difficult to identify. Some experimental studies showed that reading from hard copy material is better for proofreading or visual search tasks and also indicated that reading from screen may lead to greater fatigue and slower reading times. In contrast, numerous studies have found that the speed of reading from computer screens was slower than that from printed pages (e.g. Gould \& Grischkowsky, 1984; Heppner, Anderson, Farstrup \& Weiderman, 1985; Kruk \& Muter, 1984; Muter, Latremoullie, Treurniet \& Beam, 1982; Smith \& Savory, 1989). Even a quantitative finding indicated that screen reading was 25 per cent slower than reading from a paper version of the same material (Gould et al., 1987). Paper learners who preferred this learning medium improved their scores when the time constraints were known in advance. No such adaptation was found on screen regardless of the medium preference. (Ackerman \& Lauterman, 2012)

Although traditional paper-based text formats with linear and stable patterns of presentation have emerged over the centuries, hypertext has become a major platform for representing information on computer screens. It is widely used as an interactive medium for people to acquire knowledge. One of the many advantages of hyperlink technology is that it makes screen reading more flexible than printed pages. The term hypertext was coined by Nelson (1987) to denote non-linear text. It has been described as "nonsequential writing - text that branches and allows choices to the reader, best read at an interactive screen". For readers, this navigation involves such actions as selecting parts of the hypertext and deciding which other parts they want to jump to. During the last decade, a large number of research has been published concerning the effects of hypertext structure on user performance (e.g. Barab, Young \& Wang, 1999; Calisir \& Gurel, 2003; McDonald \& Stevenson, 1996; Potelle \& Rouet, 2003; Spruijt \& Jansen, 1999). From the viewpoints of psychology, physiology and ergonomics, there are many factors influencing people's reading comprehension performance. These factors include the linguistic surface structure, semantic cognition and individual differences in retention and prior knowledge. One variable 
that has been identified as a possible influence on reading comprehension is the amount of text that can be viewed simultaneously (Wright, 1990). Various arguments have been made for the advantages of displaying more information at the same time, from the mechanics of reading to the improvement of cognitive processing (de Bruijn, de Mul \& van Oostendorp, 1992). However, current theories of text comprehension, consider that comprehension is achieved through the construction of a multilayer mental representation of the text contents (e.g. Kintsch, 1988). The constructed mental representation allows for deeper understanding of the text, linking the reader's longterm memory and knowledge (McNamara, Kintsch, Songer \& Kintsch, 1996).

Research on age-related differences has consistently found that older adults are deficient in cognitive and linguistic abilities compared to younger adults (Wright \& Newhoff, 2002). Hawthorn (2000) indicated that the effects of ageing start to become noticeable from the mid-40s. Previous research has shown that older people do have unique needs in terms of abilities to perform computer-based tasks successfully (Hawthorn, 2000; Kelly \& Charness, 1995). Zajicek (2004) once expressed in her study that there are considerable social and economic reasons why interface designers should rise to the challenge of designing interfaces that are usable by older people. Middle-aged people between the ages of 45 and 54 are some of the important subjects in human-computer interaction (HCI) research areas. Dissimilar to current young adults who have had much more opportunity to learn computer skills since their school days, middle-aged people mostly fall short on computer literacy. However, they are considered a vital manpower resource that cannot be neglected in the national labor market and also play a major role in supporting their families ' livelihood. According to the Manpower Survey done by the Directorate-General of Budget, Accounting and Statistics, Executive Yuan, R.O.C. (2004), in Taiwan, the average unemployment rates of seniors (45-64 years of age) were 0.691 per cent in the 1980 s and 0.861 per cent in the 1990s. Their unemployment rates significantly rose to 1.75 per cent in $2000,2.92$ per cent in 2001, 3.38 per cent in 2002 and
3.76 per cent in 2003. Up to the present, middle-aged people have comprised about one sixth of the total unemployment in Taiwan, leading to a serious social problem. Except for unemployment resulting from external influences of economic recession, individual differences in vocational competence are considered an essential factor. In today's highly computerised information society, middle-aged adults must strengthen their computer literacy to face the competitive challenges of working life. For that reason, the Taiwan government has been executing an Assisting Unemployed Persons to Participate Digital Capability Enhancement Training Program since 2003. This lifelong learning project is being carried out under the auspices of the Bureau of Employment and Vocational Training, Council of Labor Affairs, Taiwan, R.O.C. Their aim is mostly targeted at unemployed individuals who involuntarily leave their jobs. The purpose of this project is to encourage unemployed adults, particularly middle-aged workers, to learn elementary computer skills, enabling them to operate computers.

With the continuing advances of information technology, computers have emerged into the mainstream of present day society. People now have greater opportunities to receive information directly from computer screens. However, many users, particularly older adult computer learners, cannot get used to operating a computer with a mouse or keyboard device, while others have trouble reading and remembering information presented on a computer screen. A previous study has found that comprehension was worse and reading was slower when reading from a computer screen compared with printed text (Belmore, 1985). This finding, however, was attributed to the subjects' lack of familiarity with computers and reading from screens. Dillon (1992) in a review of performance comparisons for reading from screen and print suggested that although the evidence was inconclusive, there appeared to be a problem for screen reading. Reading comprehension is a vital issue in human behavior and HCI research areas, which is influenced by reader's mental representation, cognitive ability and individual differences in age, gender and educational background. Although it has been widely documented in the 
literature, little evidence is available regarding reading comprehension performances of a particular user population - the middle-aged adult. Dillon and Watson (1996) stated that HCI could gain significant predictive utility if research of individual differences was related to the analysis of users in a contemporary system design. To middle-aged computer learners, how to clarify their comprehension differences between print and screen reading is of vital importance. It can help us to understand how the population of computer users performs in sequential and nonsequential interaction environments, as well as to improve hypertext design quality. Accordingly, this paper focuses on analysing the differences of reading comprehension between the two presentational formats (text on printed pages and hypertext on computer screens) in terms of middle-aged computer learners. Through the experimental study, we can also understand reader's individual differences in gender, age group and educational level with respect to reading comprehension performances of such linear and non-linear texts.

\section{2}

\section{Method}

\subsection{Task}

Reading from computer screens requires a certain degree of individual technical skill. However, most researchers did not objectively take the variable into account when conducting an experiment regarding the comparison between print and screen reading. Based on a cohort analysis, this research contained two phases: (1) an elementary computer-training course and (2) a reading comprehension test via two formulated questionnaire surveys. The first phase was a short-term computer-training course provided to middle-aged people who had no previous computer experience and were presently unemployed. The purpose of phase 1 was to have subjects use available computers. In the second phase, we analysed the differences of text comprehension between reading from print and screen in terms of these middle-aged computer learners.

\subsection{Subjects}

A total of 144 subjects were selected from the trainees of 8 terms (2-3 weeks per term) of a computer-training program, to participate in this experimental study. The participants were qualified unemployed adults who involuntarily left their jobs and the age of the subjects ranged from 45 to 54 years (i.e. "middle-aged" adults). To ensure experimental variables being equitable and objective, the participants were required to have had no computer experience before the experiment. Gender, age group and educational level classified the subjects' backgrounds, respectively, as shown in Table 1.

Table 1

Summary of subjects' backgrounds

\begin{tabular}{|l|l|c|c|}
\hline \multicolumn{2}{|l|}{ Subject's background } & Number & Percentage \\
\hline \multirow{2}{*}{ Gender } & Male & 46 & $31.9 \%$ \\
\hline \multirow{2}{*}{ Age group } & Female & 98 & $68.1 \%$ \\
\hline \multirow{3}{*}{ Educational level } & $45-49$ years old & 72 & $50.0 \%$ \\
\cline { 2 - 4 } & $50-54$ years old & 72 & $50.0 \%$ \\
\cline { 2 - 4 } & Low education (Junior high school or below the level) & 22 & $15.3 \%$ \\
\cline { 2 - 4 } & Middle education (Senior high school) & 92 & $63.9 \%$ \\
\cline { 2 - 4 } & High education (Junior college or above the level) & 30 & $20.8 \%$ \\
\hline
\end{tabular}

\subsection{Experimental design and materials}

\subsubsection{Training course}

In order to reduce the biases concerning experimental subjects' lack of familiarity with computers and reading from screens, a 36-hour training course was provided for the subjects, who learned elementary computer skills. The short-term training course, financially supported by the Bureau of Employment and Vocational Training, is the most important part of the "Assisting Unemployed Persons to Participate 
Digital Capability Enhancement Training Program". There were three units contained in the elementary course: (1) Windows operating system (12 hrs), (2) Microsoft Word (18 hrs) and (3) Internet and electronic mail (6 hrs). Each training term lasted two or three weeks (two weeks for daytime classes and three weeks for nighttime classes) with approximately 20 trainees enrolled. The training classroom was equipped with 30 Pentium personal computers, a network system and a computer broadcasting and teaching system. Each computer contained a standard mouse and keyboard for input devices and a 15" CRT monitor for output device.

\subsubsection{Questionnaire survey}

The material used in the experiment was a commercial advertisement document. The document presented a sales promotion by a local distributor of household electrical appliances, advertising different models of a particular product. The entire document was about 1,000 words (traditional Chinese) in length and the contents were arranged into three main parts: a brief introduction to the promotional activity, the details of the sales promotion and the preferential discounts given to customers. According to the QUEST model by Graesser and Franklin (1990), question answering requires the subject to identify the type of question, its focus and the relevant information sources. Rouet, Vidal-Abarca, Bert-Erboul \& Millogo (2001) found that the pattern of search varied as a function of the type of questions. Low-level or detail questions resulted in "locating and memorizing" search patterns, while high-level or main idea questions resulted in "reviewing and integrating" patterns. To test the experimental subjects' reading comprehension, we categorised the contents by the following four types of issues: namerelated, numeral, thematic and clausal issues. We also identified ten questions for the questionnaire survey as shown in Table 2 . Within the identified questions, Type 1 and Type 3 issues are relevant to literal text comprehension requiring much more word recognition, decoding and memory ability. Type 2 and Type 4 issues are related to inferential text comprehension involving a higher level of reading skills such as knowledge, reasoning and problem solving.

Table 2

List of the identified questions

\begin{tabular}{|c|c|c|}
\hline Content issue & Key word & Question \\
\hline \multirow{3}{*}{$\begin{array}{l}\text { Type 1: } \\
\text { Name-related } \\
\text { issue }\end{array}$} & Product & Which product was promoted in this advertisement? \\
\hline & Company & Which company promoted this activity? \\
\hline & Person & Who did the company invite to advertise the promotional activity? \\
\hline \multirow{3}{*}{$\begin{array}{l}\text { Type 2: } \\
\text { Numeral issue }\end{array}$} & Number & What was the special phone number for consumer service? \\
\hline & Amount & How many types of product were contained in this promotion? \\
\hline & Date & When was the deadline of this promotional activity? \\
\hline $\begin{array}{l}\text { Type 3: } \\
\text { Thematic issue }\end{array}$ & Slogan & What was the major slogan of this promotional activity? \\
\hline \multirow{3}{*}{$\begin{array}{l}\text { Type 4: } \\
\text { Clausal issue }\end{array}$} & Compensation measure & $\begin{array}{l}\text { How did the company compensate customers according to the guarantee they } \\
\text { received upon purchase? }\end{array}$ \\
\hline & Preferential scheme & What was the preferential scheme for ordering the designated types of product? \\
\hline & Installment plan & Which alternative was not included in the installment plans? \\
\hline
\end{tabular}

Past research has suggested that line lengths in printed material should not exceed about 70 characters per line (Spencer, 1968) and readers favor moderate line lengths (Tinker, 1963). When reading from screen, research has shown that longer line lengths (about 75 characters per line) were read faster with no loss of comprehension (Duchnicky \& Kolers, 1983).
However, Dyson and Haselgrove (2001) found that a medium line length (55 characters per line) appears to support effective reading at normal and fast speeds as well as producing the highest level of reading comprehension. On the other hand, Chen and Chien (2005) pointed out that the writing system of English and Chinese is essentially different. The English 
language is written from the 26-letter alphabet, which is combined in a meaningful manner to produce words. In contrast, the Chinese language has no similar alphabet, but instead there are more than 40,000 different word-images or characters and each one must be memorised individually.

Considering the experimental subjects' comparative disadvantages on cognitive and linguistic abilities, we condensed the document from 1,000 words to about 700 and presented it with two modalities: a one-page printed paper and a hypertext system, respectively. Referring to the recommendations given above, the printed page (A4 size) consisted of three paragraphs in which each line was approximately 40 Chinese characters in length. All words of the printed page were set in 14-point traditional Chinese Ming characters. Based on the contents of the printed page, we constructed a simple hypertext system by only changing related key words of the document (see Table 2). The contents of the hypertext system consisted of four data nodes where each node (page) was associated with one route so that subjects can move through the document by clicking on highlighted words appearing on the screen. In addition, each page contained two or three animated objects (e.g. blinking, jumping words, or other dynamic banner text) and most of them were relevant to the key words of the document.

According to the identified questions given in Table 2, we formulated two questionnaires to test the subjects' reading comprehension in terms of print and screen reading tasks respectively. Each questionnaire consisted of ten multiple-choice questions and was comprised of two parts. In Part 1 of the questionnaire, participants gave their personal details including gender, age range and level of education. Ten closed-ended questions were given in Part 2 of the questionnaire and each question contained four alternatives with only one correct answer.

\subsection{Procedure}

Walczyk, Kelly, Meche \& Braud (1999) explored the effects of time pressure on reading comprehension and suggested in their study that reading comprehension performance under mild time pressure was better than that under no pressure condition. Poulton (1958) once established a criterion of comprehension, i.e. that the amount remembered in a reading task, increased significantly when reading speed decreased from around 300 words per minute to about 150 words per minute. Dillon (1992) indicated that screen reading was about 20-30 per cent slower than reading from a paper version. Before the beginning of each term of the computertraining course, participants were allowed five minutes to complete the print document and then filled out the questionnaire with items related to the contents of the printed page. In order to prevent the subjects' answering experience influencing the subsequent screen reading performance, we did not tell the participants in advance about the details of the following test.

Having finished the computer-training course (i.e. after two or three weeks), participants were asked to browse the experimental hypertext for six minutes. Subsequently, the questionnaire was provided to the participants after they had browsed through the contents of the hypertext document. In this experimental study, all subjects uniformly had a certain degree of proficiency at hyperlink operation and screen reading, after they had finished the training course. In addition, subjects were encouraged to do their best to answer the questions without guessing and none of the subjects had difficulty completing both the print and hypertext documents within the time allotted.

\subsubsection{Scoring and data analysis}

Reading comprehension often takes the form of asking participants questions about the content of the material read, so the level of comprehension that is derived from the number of correct responses can be measured. The dependent measure in this experiment was subjects' reading comprehension. To assess the subjects' comprehension, a score was derived by totaling the number of correct answers given. Each correct response scored one point with the full score being ten points in each reading comprehension test. All statistical analyses were computed using the Statistical Product \& Service Solutions (SPSS) software. Analysis of variance (one-way ANOVA) was conducted on the dependent measures. This study used $\alpha=0.05$ to check whether significant differences existed between the dependent measures or not. In addition to measuring the subjects' 
comprehension differences between print and screen reading, individual differences in gender, age group and education were also analysed.

3

\section{Results}

\subsection{Comprehension differences between print and screen reading}

The descriptive statistics of the experimental results are shown in Table 3. The mean score of comprehension measures in print reading was 5.36 (S.D.=1.49) while that in screen reading was $5.50($ S.D. $=1.82)$. Screen reading was better than print reading in terms of the middle-aged subjects. A one-way ANOVA was used to determine whether significant differences existed between the comprehension measures. The result showed that the comprehension differences between print and screen reading were not statistically significant at the level of $\alpha=0.05(F(1,286)=0.501, P=0.48>0.05)$.

Table 3

Descriptive statistics for reading comprehension measures

\begin{tabular}{|c|c|c|c|c|c|c|}
\cline { 3 - 7 } \multicolumn{1}{c|}{} & N. & Mean & Std. deviation & Std. error mean & Max. & Min. \\
\hline Print reading & \multirow{2}{*}{144} & 5.36 & 1.49 & 0.12 & 9 & 2 \\
\cline { 1 - 6 } Screen reading & & 5.50 & 1.82 & 0.15 & 10 & 1 \\
\hline
\end{tabular}

As shown in Table 4, the correct rates of the print reading comprehension test questions were 92.1 per cent in type 1, 42.1 per cent in type 2, 56.9 per cent in type 3 and 25.5 per cent in type 4 and those of the screen reading comprehension test questions were 69.4 per cent in type $1,57.9$ per cent in type 2, 37.5 per cent in type 3 and 43.5 per cent in type 4 . With print reading, subjects had better comprehension than with screen reading in terms of type 1 and type 3 questions. Conversely, reading from screen was better than from print in terms of subjects' reading comprehension towards type 2 and type 4 questions.

Table 4

Correct rates of reading comprehension tests for different types of questions

\begin{tabular}{|c|c|c|c|c|c|}
\hline \multicolumn{2}{|c|}{} & $\begin{array}{c}\text { Type 1 } \\
(\mathrm{N} . \mathrm{Q}=3)\end{array}$ & $\begin{array}{c}\text { Type 2 } \\
(\mathrm{N} . \mathrm{Q} .=3)\end{array}$ & $\begin{array}{c}\text { Type 3 } \\
(\mathrm{N} . \mathrm{Q}=1)\end{array}$ & $\begin{array}{c}\text { Type 4 } \\
(\mathrm{N} . \mathrm{Q} .=3)\end{array}$ \\
\hline \multirow{2}{*}{$\begin{array}{c}\text { Print reading } \\
(\mathrm{N}=144)\end{array}$} & Frequency & 398 & 182 & 82 & 110 \\
\hline \multirow{2}{*}{$\begin{array}{c}\text { Screen reading } \\
(\mathrm{N}=144)\end{array}$} & Correct rate & $92.1 \%$ & $42.1 \%$ & $56.9 \%$ & $25.5 \%$ \\
\cline { 2 - 7 } & Frequency & 300 & 250 & 54 & 188 \\
\hline
\end{tabular}

\subsection{Gender effect on reading comprehension performance}

As shown in Table 5, the mean scores of comprehension measures were 4.96 (S.D. $=1.44$ ) for the male subjects and 5.55 (S.D.=1.48) for the female subjects in terms of the print reading test, while the male subjects were 5.52 (S.D. $=2.06)$ and the female subjects were 5.49 (S.D.=1.71) in terms of the screen reading test. Females were better on print reading, whereas males had better comprehension performance with screen reading. A one-way ANOVA was used to check the dependent measures. The result of ANOVA showed that gender effect on print reading comprehension performance was significant $(F(1,142)=5.132, P=0.025<0.05)$, while that on screen reading comprehension performance was not significant $(F(1,142)=0.01, P=0.922>0.05)$. As shown in Table 6 , female subjects had higher correct rates in type 1 , type 2 and type 4 questions in terms of the print reading comprehension test. With respect to screen reading comprehension performance, male subjects were better in type 3 and type 4 questions. It is worth noting that there was a significant increase in comprehension with screen reading for the male subjects in Type 4 questions. 


\section{Table 5}

Descriptive statistics for reading comprehension measures in terms of subjects' individual differences in gender, age group and educational level

\begin{tabular}{|c|c|c|c|c|c|c|c|}
\hline & & & & & & & \\
\hline & & & N. & Mean & S.D. & Max. & Min. \\
\hline \multirow{4}{*}{ Gender } & \multirow{2}{*}{ Print reading } & Male & 46 & 4.96 & 1.44 & 7 & 3 \\
\hline & & Female & 98 & 5.55 & 1.48 & 9 & 2 \\
\hline & \multirow{2}{*}{ Screen reading } & Male & 46 & 5.52 & 2.06 & 10 & 2 \\
\hline & & Female & 98 & 5.49 & 1.71 & 9 & 1 \\
\hline \multirow{4}{*}{ Age group } & \multirow{2}{*}{ Print reading } & $45-49$ years old & 72 & 5.58 & 1.63 & 9 & 2 \\
\hline & & $50-54$ years old & 72 & 5.14 & 1.30 & 7 & 3 \\
\hline & \multirow{2}{*}{ Screen reading } & $45-49$ years old & 72 & 5.75 & 1.70 & 9 & 2 \\
\hline & & $50-54$ years old & 72 & 5.25 & 1.92 & 10 & 1 \\
\hline \multirow{6}{*}{$\begin{array}{l}\text { Educational } \\
\text { level }\end{array}$} & \multirow{3}{*}{ Print reading } & Low education & 22 & 4.64 & 0.90 & 6 & 3 \\
\hline & & Middle education & 92 & 5.52 & 1.49 & 8 & 2 \\
\hline & & High education & 30 & 5.40 & 1.69 & 9 & 3 \\
\hline & \multirow{3}{*}{ Screen reading } & Low education & 22 & 5.09 & 1.34 & 7 & 3 \\
\hline & & Middle education & 92 & 5.43 & 1.93 & 10 & 1 \\
\hline & & High education & 30 & 6.00 & 1.74 & 8 & 2 \\
\hline
\end{tabular}

\subsection{Age group effect on reading comprehension performance}

The mean scores of comprehension measures for the middle-aged computer learners aged from 45 to 49 years were 5.58 (S.D. $=1.63)$ on the print reading test and 5.75 (S.D. $=1.70)$ on the screen reading test. For those subjects aged 50 to 54 years, the mean scores of comprehension measures were 5.14 (S.D.=1.30) on the print reading test and 5.25 (S.D. $=1.92$ ) on the screen-reading test (see Table 5). Irrespective of print or screen reading, the younger age group had better reading comprehension than the older age group. However, the results of ANOVA indicated that the age group effect on both the print $(F(1,142)=3.256, P=0.073>0.05)$ and screen $(F(1,142)=2.737, P=0.1>0.05)$ reading comprehension performances, was not statistically significant. Except for Type 1 questions in the screen reading test and Type 4 questions in the print reading test, the younger age group (4549 years old) had higher correct rates of comprehension scoring than the older age group (50-54 years old) (see Table 6).

\subsection{Education effect on reading comprehension performance}

With respect to the education effect on print reading comprehension performance, the mean scores of comprehension measures were 4.64 (S.D. $=0.90)$ for the low education subjects, 5.52 (S.D. $=1.49$ ) for the middle education subjects and 5.40 (S.D.=1.69) for the high education subjects (see Table 5). In the screen reading test, the mean scores of comprehension measures were 5.09 (S.D.=1.34) for the low education subjects, 5.43 (S.D.=1.93) for the middle education subjects and 6.00 (S.D.=1.74) for the high education subjects (see Table 5). In general, the middle-aged computer learners that have higher education had better reading comprehension. However, the result of ANOVA showed that the main effect of educational level on print reading comprehension performance was statistically significant $(F(2,141)=3.249, P=0.042<0.05)$, while that on screen reading comprehension performance was not significant $(F(2,141)=1.757, P=0.176>0.05)$. Of the three different subject groups (see Table 6), the low education subject group had the best comprehension performance in Type 1 but the worst in Type 4 questions within the print reading test. Both the low education and high education subject groups made an obvious comprehension improvement in Type 2 and Type 4, while both middle education and high education subject groups did worse in Type 3 questions within the screen reading test. 
Table 6

Correct rates of comprehension scoring in terms of subjects' individual differences in gender, age group and educational level

\begin{tabular}{|c|c|c|c|c|c|c|}
\hline \\
\hline & & & Type 1 & Type 2 & Type 3 & Type 4 \\
\hline \multirow{4}{*}{ Gender } & \multirow{2}{*}{$\begin{array}{l}\text { Male } \\
(N=46)\end{array}$} & Print reading & $88.4 \%$ & $36.2 \%$ & $65.2 \%$ & $18.8 \%$ \\
\hline & & Screen reading & $65.2 \%$ & $50.7 \%$ & $47.8 \%$ & $52.2 \%$ \\
\hline & \multirow{2}{*}{$\begin{array}{l}\text { Female } \\
(\mathrm{N}=98)\end{array}$} & Print reading & $93.9 \%$ & $44.9 \%$ & $53.1 \%$ & $28.6 \%$ \\
\hline & & Screen reading & $71.4 \%$ & $61.2 \%$ & $32.7 \%$ & $39.5 \%$ \\
\hline \multirow{4}{*}{ Age group } & \multirow{2}{*}{$\begin{array}{l}45-49 \text { years old } \\
(\mathrm{N}=72)\end{array}$} & Print reading & $97.2 \%$ & $42.6 \%$ & $63.9 \%$ & $25.0 \%$ \\
\hline & & Screen reading & $68.5 \%$ & $58.3 \%$ & $38.9 \%$ & $51.9 \%$ \\
\hline & \multirow{2}{*}{$\begin{array}{l}50-54 \text { years old } \\
(\mathrm{N}=72)\end{array}$} & Print reading & $87.0 \%$ & $41.7 \%$ & $50.0 \%$ & $25.9 \%$ \\
\hline & & Screen reading & $70.4 \%$ & $57.4 \%$ & $36.1 \%$ & $35.2 \%$ \\
\hline \multirow{6}{*}{$\begin{array}{l}\text { Educational } \\
\text { level }\end{array}$} & \multirow{2}{*}{$\begin{array}{l}\text { Low education } \\
(\mathrm{N}=22)\end{array}$} & Print reading & $97.0 \%$ & $36.4 \%$ & $45.5 \%$ & $6.1 \%$ \\
\hline & & Screen reading & $51.5 \%$ & $60.6 \%$ & $45.5 \%$ & $42.4 \%$ \\
\hline & \multirow{2}{*}{$\begin{array}{l}\text { Middle education } \\
(\mathrm{N}=92)\end{array}$} & Print reading & $91.3 \%$ & $45.7 \%$ & $60.9 \%$ & $26.8 \%$ \\
\hline & & Screen reading & $72.5 \%$ & $57.2 \%$ & $37.0 \%$ & $39.1 \%$ \\
\hline & \multirow{2}{*}{$\begin{array}{l}\text { High education } \\
(\mathrm{N}=30)\end{array}$} & Print reading & $91.1 \%$ & $35.6 \%$ & $53.3 \%$ & $35.6 \%$ \\
\hline & & Screen reading & $73.3 \%$ & $57.8 \%$ & $33.3 \%$ & $57.8 \%$ \\
\hline
\end{tabular}

4

\section{Discussion}

Research on comparing print and screen reading performance has largely been conducted since the $1980 \mathrm{~s}$, but results seem rather inconsistent. The findings from previous studies were mostly inconclusive and tended towards screen reading eliciting poorer user performance. Regarding comprehension differences between print and screen reading, some earlier research found that comprehension was worse when reading from screen compared with print (e.g. Belmore, 1985; Gould et al., 1987). However, some studies reported no significant differences between levels of comprehension for screen and print presentations (e.g. Mayes, Sims \& Koonce, 2001; Noyes \& Garland, 2003; Rice, 1994), while some indicated only minimal differences between the two presentational formats (e.g. Cushman, 1986; Muter \& Maurutto, 1991; Oborne \& Holton, 1988). Noyes and Garland (2003) explained that the inconsistency in the findings appears primarily due to variations in the methodologies employed; different experimental designs make comparative interpretation difficult, especially where the computer-based learning format is used as an adjunct to paper-based instruction, or where study time is not matched. In addition to experimental materials and procedures, subject selection is an essential variable that must be prudently considered as reading performance highly entails individual mental and cognitive skills, including inference, retention, prior knowledge and academic ability.

Based on a cohort analysis, this study focuses on a specific user population - the middle-aged computer learners, by whom we attempt to control and match the possible variables with respect to participants' reading ability and computer literacy. In the experimental study, we found that comprehension was slightly better when reading from screen compared with print. However, the differences between levels of comprehension for the two presentational formats were not significant in terms of the middle-aged subjects. Additionally, analysing of the correct rates of comprehension scoring in print reading, the middle-aged subjects had a clearer comprehension in terms of the namerelated and thematic content issues. However, while reading from screen elicited better comprehension performance in terms of the numeral and clausal issues. It is noteworthy to remark that the correct rates of print reading in the name-related content issue reached a relatively high level of 92.1 per cent, while screen reading resulted in a 70.6 per cent increase in comprehension scoring of the clausal content issue over print reading. In contrast, linear texts of traditional paper-based material are superior for the middle-aged readers' literal text comprehension as such 
familiar presentation helps them to locate and memorise information for proofreading or visual search tasks. However, hypertext is beneficial to the readers' inferential text comprehension, since its interactive flexibility supports them in reviewing and integrating information for yielding a deeper understanding of the text. Weiss, Knowlton \& Morrison (2002) indicated that the use of hypertext with animated objects fosters various interactions that a text-only interface is unlikely to achieve. Jonassen $(1988$; 1991) expressed the opinion that hypertext should facilitate learning, because of its correspondence with human associative memory structures, that works with the natural human modality of encoding and retrieving information. To middle-aged adults, as mentioned by Mayes et al. (2001), it is important to consider the nature of the information before determining the medium used, since not only the formatting but the medium can impact user performance as well.

In respect of gender effect on reading comprehension performance, females were better on print reading, whereas males were superior on screen reading. It significantly resulted in about a 2.78 times increase in comprehension scoring of the clausal content issue over print reading. However, gender effect on print reading comprehension performance was significant while that on screen reading comprehension performance was not significant. Gender differences are quite an important issue that has been widely explored in both social and behavioral science research areas. Some research found that females had lower perceptions of individual ability and lower self-confidence in computers than males did (e.g. Busch, 1995; Shashaani \& Khalili, 2001; Torkzadeh \& Koufteros, 1994). However, Dickhäuser and Stiensmeier-Pelster (2002) argued that gender differences in computer works emerge only with regard to self-concept of ability and expectancy. Within our experimental findings, female subjects are better at print reading comprehension performance, but hypertext seems to be an advantageous medium for them to improve their inferential text comprehension. As usual, linear texts of traditional hard copy material might still play a major role in middle-aged adults' reading activity, but we believe that appropriate employment of hypertext documents can provide reading performance that is quite comparable to traditional hard copy material.

Successful reading comprehension requires high-level linguistic skills and cognitive abilities. In the literature on aging, some researchers indicated that aging negatively affects processing of information (e.g. Gick, Craik \& Morris, 1988; Morris, Gick \& Griak, 1988), while others claimed that aging negatively affects capacity of storage (e.g. Babcock \& Salthouse, 1990; Salthouse, Babcock \& Shaw, 1991). In middle-aged computer learners, we found that the younger age group (45-49 years old) had superior reading comprehension than the older age group (50-54 years old), regardless of the print or screen reading comprehension test. Particularly, screen reading gave the younger age group about a 2.1 increase in comprehension scoring of the clausal content issue over print reading. However, age group effect on both print and screen reading comprehension was not significant. Van der Linden, Hupet, Feyereisen, Schelestraete, Bestgen, Bruyen, Lories, Ahmadi \& Seron (1999) pointed out that there is a significant, indirect relationship between age and language comprehension., Indeed, it is mediated through an age-related decline in processing speed, inhibitive efficiency and working memory capacity. According to Wright and Newhoff (2002), age-related differences did emerge on inferential abilities and a significant correlation emerged between the older group's performance on comprehension revisions and their working memory capacity. However, Brebion, Ehrlich and Tardieu (1995) suggested that it is not that the processing or storage component is deficient in older adults' working memory capacity; rather, older adults have a general reduction in cognitive resources, with fewer resources available for each component.

In the literature, reading performance has often been assessed according to the subjects' academic ability or prior knowledge. Regarding the main effect of an individual's educational level on reading comprehension performance, we found that the higher education subject groups generally had a better reading comprehension. However, comprehension differences among the three subject groups were significant 
in terms of the print reading test, while insignificant in terms of the screen reading test. Surprisingly, the low education subject group had the highest correct rates of print reading comprehension scoring in the namerelated content issue. However, their correct rates of print reading comprehension scoring in the clausal content issue were exceedingly low. Screen reading results showed both the low education and high education subject groups had an obvious comprehension improvement in the numeral and clausal content issues against print reading. This resulted in about a 6.95 times increase in comprehension scoring of the clausal content issue for the low education subject group. However, it got worse when the middle education and high education subject groups performed in the thematic content issue, compared with print reading. Although traditional hard copy material tends to be thought of as a more habitual reading manner, without the use of technology, hypertext can be considered a practicable medium for middle-aged adults. Such interactive presentation provides them with a positive impact on cognitive processing, regardless of their academic ability or prior knowledge.

\section{5}

\section{Conclusion}

Reading is a pervasive and vital activity in our lives, requiring many mental and cognitive processes. With the incredible and fast-paced advances being made in computer technology, people have greater opportunities to read information directly on a computer screen. Although research on comparing print and screen reading performance has largely been carried out during the past two decades, the findings from previous studies seem rather inconclusive and inconsistent. Reading from screen requires a certain degree of individual computer literacy. However, most researchers did not objectively take this variable into account when conducting experiments regarding the comparison between the two presentational formats. Accordingly, the present study focuses on a particular user population - the middleaged adult. We attempt to control and match the possible variables through two phases of experimental design: (1) an elementary computer- training course to enable experimental subjects the use of available computers and (2) a reading comprehension test via two formulated questionnaire surveys.

In our experimental findings, there were no significant differences between levels of reading comprehension for print and screen presentations in terms of middle-aged computer learners. With regard to individual differences in gender, age group and educational level, gender and education effects on print reading comprehension performance were significant, while those on screen reading comprehension performance were not significant. To middleaged computer learners, the main effect of age group on both print and screen reading comprehension performances was insignificant. Print reading for middle-aged subjects had a comparatively higher level of comprehension performance towards the name-related content issue, while screen reading elicited an obvious comprehension improvement in terms of the clausal content issue within the reading comprehension test. Reading can be regarded as an interactive modality between readers and material they read, by means of different types of media. As a whole, linear texts of traditional paper-based material are better for middleaged readers' literal text comprehension. This tells us that a familiar presentation helps them to locate and memorise information for proofreading or visual search tasks. Hypertext, on the other hand is beneficial to their inferential text comprehension, since its interactive flexibility supports them to review and integrate information, for yielding a deeper understanding of the text. These findings can be used as guidelines for specific HCI design features.

Although traditional paper-based text formats have emerged over the centuries, hypertext has become a major platform for representing information on computer screens and is widely used as a medium for people to acquire knowledge. Most of the earlier research showed that an individual's reading performance decreased when reading from screen compared with print. However, Noyes and Garland (2003) indicated that it is not the case today. Reading comprehension involves a highly complex interplay of cognitive processes. Past researchers suggested that interactive multimedia 
could be considered as a cognitive tool that extends people's senses (e.g. Buchanan, Zellweger \& Pier, 1993; Mayer, 2003). Some studies indicated that the navigation difficulty in hypertext systems is common to older users (e.g. Lin, 2003; 2004). However, Calcaterra, Antonietti and Underwood (2005) found that hypermedia navigation behavior was linked to computer skills rather than to cognitive style and that learning outcomes were unaffected by cognitive style or by computer skills. With our experimental findings, we suggest that hypermedia could be used as a cognitive tool for improving middle-aged adults' inferential abilities on reading comprehension; provided that they were trained adequately to use available computers. Further research should focus on analysing how the middle-aged adults' cognitive processes relate to hypermedia performance in terms of their inferential abilities on reading comprehension.

\footnotetext{
Acknowledgement

The authors are grateful to the valuable comments made by the reviewers.

${ }^{*}$ CORRESPONDING AUTHOR CONTACT

Chich-Jen Shieh, charles@mail.cjcu.edu.tw
}

\section{References}

ACKERMAN, R \& LAUTERMAN, T. 2012. Taking reading comprehension exams on screen or on paper? A metacognitive analysis of learning texts under time pressure. Computers in Human Behavior, 28(5): 1816-1828

AGARWAL-HOLLANDS, U. \& ANDREWS, R. 2001. From scroll...to codex.... and back again. Education, Communication \& Information, 1(1):59-73.

BABCOCK, R.L. \& SALTHOUSE, T. A. 1990. Effects of increased processing demands on age-differences in working memory. Psychology and Aging, 5:421-428.

BARAB, S.A., YOUNG, M.F. \& WANG, J. 1999. The effects of navigational and generative activities in hypertext learning on problem solving and comprehension. International Journal of Instructional Media, 26: 283-301.

BELMORE, S.M. 1985. Reading computer-presented text. Bulletin of the Psychonomic Society, 23(1):12-14. BREBION, G., EHRLICH, M-F. \& TARDIEU, H. 1995. Working memory in older subjects: Dealing with ongoing and stored information in language comprehension. Psychological Research, 58:225-232.

BUCHANAN, M., ZELLWEGER, P. \& PIER, K. 1993. Multimedia documents as user interface. In Proceedings of CHI'93. New York: ACM.

BUSCH, T. 1995. Gender differences in self-efficacy and attitudes toward computers. Journal of Educational Computing Research, 12(2):147-158.

CALCATERRA, A., ANTONIETTI, A. \& UNDERWOOD, J. 2005. Cognitive style, hypermedia navigation and learning. Computers and Education, 44:441-457.

CALISIR, F. \& GUREL, Z. 2003. Influence of text structure and prior knowledge of the learner on reading comprehension, browsing and perceived control. Computers in Human Behavior, 19:135-145.

CHEN, C.H. \& CHIEN, Y.H. 2005. Reading Chinese text on a small screen with RSVP. Displays, 26: 103-108.

CORNOLDI, C. \& OAKHILL, J. (eds.) 1996. Reading comprehension difficulties: processes and intervention. Mahwah, NJ: Erlbaum.

CUSHMAN, W.H. 1986. Reading from microfiche, VDT and the printed page: subjective fatigue and performance. Human Factors, 28(1):63-73.

DE BRUIJN, D., DE MUL, S. \& VAN OOSTENDORP, H. 1992. The influence of screen size and text layout on the study of text. Behavior \& Information Technology, 11:71-78.

DICKHÄUSER, O. \& STIENSMEIER-PELSTER, J. 2002. Gender differences in computer work: evidence for the model of achievement-related choices. Contemporary Educational Psychology, 27:486-496.

DILLON, A. 1992. Reading from paper versus screens: a critical review of the empirical literature. Ergonomics, 35(10):1297-1326. 
DILLON, A. \& WATSON, C. 1996. User analysis in HCI: the historical lesson from individual differences research. International Journal of Human-Computer Studies, 45(6):619-637.

DIRECTORATE-GENERAL OF BUDGET, ACCOUNTING AND STATISTICS, EXECUTIVE YUAN, R.O.C. 2004. Statistical Yearbook of the Republic of China. Taipei, Taiwan: Government Bookstore. http://www.stat.gov.tw/bs2/YearBook.htm

DUCHNICKY, R.L. \& KOLERS, P.A. 1983. Readability of text scrolled on visual display terminals as a function of window size. Human Factors, 25:683-692.

DYSON, M.C. \& HASELGROVE, M. 2001. The influence of reading speed and line length on the effectiveness of reading from screen. International Journal of Human-Computer Studies, 54:585-612. GICK, M.L., CRAIK, F.I.M. \& MORRIS, R.G. 1988. Task complexity and age differences in working memory. Memory and Cognition, 16:353-361.

GOUGH, P.B. \& TUNMER, W.E. 1986. Decoding, reading and reading disability. Remedial and Special Education, 7:6-10.

GOUGH, P.B., JUEL, C. \& GRIFFITH, P.L. 1992. Reading, spelling and the orthographic cipher. In: Gough, Ehri \& Treiman (eds.) Reading comprehension difficulties. Processes and intervention. Mahwah, NJ: Erlbaum.

GOULD, J.D. \& GRISCHKOWSKY, N. 1984. Doing the same work with hard copy and cathode ray tube (CRT) computer terminals. Human Factors, 26:323-337.

GOULD, J.D., ALFARO, L., BARNES, V., FINN, R., GRISCHKOWSKY, N. \& MINUTO, A. 1987. Reading is slower from CRT displays than from paper: attempts to isolate a single-variable explanation. Human Factors, 29:269-299.

GRAESSER, A.C. \& FRANKLIN, S.P. 1990. QUEST: a model of question answering. Discourse Processes, 13:279-303.

GRAESSER, A.C., SINGER, M. \& TRABASSO, T. 1994. Constructing inferences during narrative text comprehension. Psychological Review, 101(3):371-395.

HARPSTER, J. L. 1989. Visual performance on CRT display than from paper: attempts to isolate a singlevariable explanation. Human Factors, 29:247-257.

HANSEN, W.J. \& HAAS, C. 1988. Reading and writing with computers: a framework for explaining differences in performance. Communications of the ACM, 31:1080-1089.

HAWTHORN, D. 2000. Possible implications of aging for interface designers. Interacting with Computers, 12:507-528.

HEPPNER, F. ANDERSON, J., FARSTRUP, A. \& WEIDERMAN, N. 1985. Reading performance on a standardised test is better from print than from computer display. Journal of Reading, 28:321-325.

JONASSEN, D.H. 1988. Designing structured hypertext and structuring access to hypertext. Educational Technology, 28:13-16.

JONASSEN, D.H. 1991. Evaluating constructivistic learning. Educational Technology, 39:28-33.

JUST, M.A. \& CARPENTER, P.A. 1987. The psychology of reading and language comprehension. Newton, MA: Allyn \& Bacon.

KELLY, C.L. \& CHARNESS, N. 1995. Issues in training older adults to use computers. Behaviour and Information Technology, 14:107-120.

KINTSCH, W. 1988. The role of knowledge in discourse comprehension: a construction-integration model. Psychological Review, 95:163-182.

KRUK, R.S. \& MUTER, P. 1984. Reading of continuous text on video screens. Human Factors, 26: 339-345. LIN, D.-Y. M. 2003. Hypertext for the aged: effects of text topologies. Computers in Human Behavior, 19: 201-209.

LIN, D.-Y. M. 2004. Evaluating older adults' retention in hypertext perusal: impacts of presentation media as a function of text topology. Computers in Human Behavior, 20:491-503.

MANGEN, A. WALGERMO, B.R. \& BRØNNICK, K. 2013. Reading linear texts on paper versus computer screen: Effects on reading comprehension, International Journal of Educational Research, 58:61-68.

MAYER, R.E. 2003. The promise of multimedia learning: using the same instructional design methods across different media. Learning and Instruction, 13:125-139. 
MAYES, D.K., SIMS, V.K. \& KOONCE, J.M. 2001. Comprehension and workload differences for VDT and paper-based reading. International Journal of Industrial Ergonomics, 28:367-378.

MCDONALD, S. \& STEVENSON, R.J. 1996. Disorientation in hypertext: the effects of the three text structures on navigation performance. Applied Ergonomics, 27(1):61-68.

MCNAMARA, D.S., KINTSCH, E., SONGER, N.B. \& KINTSCH, W. 1996. Are good texts always better? Interactions of text coherence background, knowledge and levels of understanding in learning from text. Cognition and Instruction, 14(1):1-43.

MORRIS, R.G., GICK, M.L. \& GRIAK, F.I.M. 1988. Processing resources and age differences in working memory. Memory and Cognition, 16:362-366.

MUTER, P., LATREMOULLIE, S.A., TREURNIET, W.C. \& BEAM, P. 1982. Extended reading of continuous text on television screens. Human Factors, 24(5):501-508.

MUTER, P. \& MAURUTTO, P. 1991. Reading and skimming from computer screens and books: the paperless office revisited? Behaviour and Information Technology, 10(4):257-266.

NELSON, T.H. 1987. Literary machines, N.p.: Theodore Nelson.

NOYES, J.M. \& GARLAND, K.J. 2003. VDT versus paper-based text: reply to Mayes, Sims and Koonce. International Journal of Industrial Ergonomics, 31:411-423.

OAKHILL, J. \& YUILL, N. 1996. Higher order factors in comprehension disability: processes and remediation. In: Cornoldi and Oakhill (eds.) Reading comprehension difficulties. Processes and intervention, 71-92. Mahwah, NJ: Erlbaum.

OBORNE, D.J. \& HOLTON, D. 1988. Reading from screen versus paper: there is no difference. International Journal of Man-Machine Studies, 28(1):1-9.

PERFETTI, C.A. 1985. Reading ability. New York: Oxford University Press.

PIOLAT, A., ROUSSEY, J.-Y. \& THUNIN, O. 1997. Effects of screen presentation on text reading and revising. International Journal of Human-Computer Studies, 47:565-589.

POTELLE, H. \& ROUET, J.-F. 2003. Effects of content representation and readers' prior knowledge on the comprehension of hypertext. International Journal of Hunan-Computer Studies, 58:327-345.

POULTON, E.C. 1958. Time for reading and memory. The British Journal of Psychology, 49:230-245.

RICE, G. 1994. Examining constructs in reading comprehension using two presentation modes: Paper vs. computer. Journal of Educational Computing Research, 11:153-178.

ROUET, J. -F., VIDAL-ABARCA, E., BERT-ERBOUL, A. \& MILLOGO, V. 2001. Effects of information search tasks on the comprehension of instructional text. Discourse Processes, 31(2):163-186.

SALTHOUSE, T.A., BABCOCK, R.L. \& SHAW, R.J. 1991. Effects of adults' age on structural and operational capacities in working memory. Psychology and Aging, 6:118-127.

SEYMOUR, P.H.K. \& EVANS, H.M. 1994. Levels of phonological awareness and learning to read. Reading and Writing: An Interdisciplinary Journal, 6:221-250.

SHASHAANI, L. \& KHALILI, A. 2001. Gender and computers: similarities and differences in Iranian college students' attitudes toward computers. Computers and Education, 37:363-375.

SINATRA, G.M. \& ROYER, J.M. 1993. Development of cognitive component processing skills that support skilled reading. Journal of Educational Psychology, 85:509-519.

SMITH, A. \& SAVORY, M. 1989. Effects and after-effects of working at a VDU: investigation of the influence of personal variables. In: Megaw (eds.) Contemporary Ergonomics. London: Taylor \& Francis. SPENCER, H. 1968. The visible word. London: Royal College of Art.

SPRUIJT, S. \& JANSEN, C. 1999. Influence of task and format on reading results with an online text. IEEE Transactions on Professional Communication, 42(2):92-99.

STANOVICH, K.E. 1986. Matthew effects in reading: some consequences of individual differences in the acquisition of literacy. Reading Research Quarterly, 21:360-407.

TINKER, M.A. 1963. Legibility of print. Ames: Iowa State University Press.

TORKZADEH, G. \& KOUFTEROS, X. 1994. Factorial validity of a computer self-efficacy scale and the impact of computer training. Educational and Psychological Measurement, 54(3):813-821.

VAN DER LINDEN, M., HUPET, M., FEYEREISEN, P., SCHELESTRAETE, M-A., BESTGEN, Y., BRUYER, R., LORIES, G., EL AHMADI, A. \& SERON, X. 1999. Cognitive mediators of age-related 
differences in language comprehension and verbal memory performance. Aging, Neuropsychology and Cognition, 6:32-55.

WAGNER, R.K., TORGESEN, J.K. \& RASHOTTE, C.A. 1994. Development of reading-related phonological processing abilities: New evidence of bi-directional causality from a latent variable longitudinal study. Developmental Psychology, 30:73-87.

WALCZYK, J.J., KELLY, K.E., MECHE, S.D. \& BRAUD, H. 1999. Time limitation enhances reading comprehension. Contemporary Educational Psychology, 24:156-165.

WEISS, R.E., KNOWLTON, D.S. \& MORRISON, G.R. 2002. Principles for using animation in computerbased instruction: theoretical heuristics for effective design. Computers in Human Behavior, 18:465-477.

WRIGHT, P. 1990. Hypertexts as an interface for learners: some human factors issues. In: Jonassen \& Mandl (eds.) Designing hypermedia for learning. Berlin: Springer-Verlar.

WRIGHT, H.H. \& NEWHOFF, M. 2002. Age-related differences in inference revision processing. Brain and Language, 80:226-239.

ZAJICEK, M. 2004. Successful and available: interface design exemplars for older user. Interacting with Computers, 16:411-430. 